\title{
DEFORMITY CORRECTION IN SEVERE ANKYLOSING SPONDYLITIS WITH COMBINED OSTEOTOMIES
}

\author{
๑ Görkem KIYAK', ๑ Murat BEZER² \\ ${ }^{1}$ Academic Hospital, Clinic of Orthopaedic Surgery, Istanbul, Turkey \\ 2 Marmara University Faculty of Medicine, Department of Orthopaedic Surgery, İstanbul, Turkey
}

\begin{abstract}
Objective: To evaluate the effects of single-level lumbar decancellation osteotomy combined with multiple level polysegmental posterior osteotomies involving the whole thoracal spine in severe ankylosing spondylitis.

Materials and Methods: Between 2008 and 2017, 14 patients (12 men and two women) were included in the study. The indication for surgery was a progressive loss of horizontal sight due to whole spine kyphosis (chin-brow angle over $90^{\circ}$ ). The mean age at the time of operation was 47 years. Preoperatively and postoperatively, the cobb angle was measured on standing lateral radiographs of the whole spine. The chin-brow angle correction was recorded.

Results: The mean surgical time was 281 minutes, and the average blood loss was $1870 \mathrm{~mL}$. Preoperative mean chin-brow angle was $97.5^{\circ}$. Postoperative chin-brow angle was $18^{\circ}(\mathrm{p}<0.0001)$. The preoperative mean thoracic cobb angle was $69^{\circ}$, and the postoperative thoracic cobb angle was $37.5^{\circ}(p<0.0001)$. The preoperative mean lumbar lordosis angle was $-1.2^{\circ}$, and the postoperative mean lumbar lordosis angle was $-29^{\circ}(p<0.0001)$. There were no major perioperative and postoperative complications. Two patients had minor wound healing problems. Bone healing was satisfactory in all patients. Three patients had a loss of correction in thoracal regions of 5, 7, and 8 degrees at the final follow-up visit. Reduction losses were acceptable, and we did not plan any revision surgeries.

Conclusion: Our study showed that this surgical method is as effective as two-level lumbar osteotomies used in severe cases and is also a safer procedure as the latter.
\end{abstract}

Keywords: Ankylosing spondylitis, osteotomy, deformity

\section{INTRODUCTION}

There are two subtypes of kyphotic deformity in ankylosing spondylitis: Thoracic kyphosis with either preservation of lumbar lordosis or loss of lumbar lordosis resulting in a prolonged $\mathrm{C}$ flexion deformity of the whole spine.

When the whole trunk becomes a long $\mathrm{C}$ curve to maintain the visual arc, patients have to flex their knees. This results in a very uncomfortable and energy-demanding posture. When patients try to extend their knees, stiff cervical and upper thoracic spinal regions limit the forward visual to only a few meters in front of them.

The correction of lumbar kyphosis in ankylosing spondylitis was first popularized by Smith-Petersen et al.(1). Multiple inverted V-shaped posterior osteotomies were closed by spine extension, rupture of the anterior longitudinal ligament, and opening of the anterior part of the intervertebral disc.

Later, osteotomies involving vertebral bodies to gain more angular correction at a single-level were described by many authors ${ }^{(2-4)}$. Today, these osteotomies are frequently in use either as single-level osteotomy or interrupted two-level osteotomy to correct kyphotic deformity in ankylosing spondylitis( ${ }^{(5-7)}$.

These osteotomies are performed on the lumbar and thoracolumbar junction, where a surgeon can achieve the most angular correction, leaving the upper thoracic kyphosis untreated. This limits the correction of visual arc when there is a severe kyphotic deformity in the thoracic region.

This paper reports the results of the correction of whole spinal column kyphotic deformity using single-level lumbar decancellation osteotomy in combination with multiple level polysegmental posterior osteotomies and fixation with long posterior construct up to T2 level.

\section{MATERIAL AND METHODS}

Approval from the General Clinical Directorate of Academic Hospital was obtained before starting the data collection of 
patients included in the study. The study was performed by the ethical standards of the 1964 Declaration of Helsinki as revised in 2000 and those of Good Clinical Practice (approval number: 10/01/2019-12).

All subjects participating in this retrospective study received a thorough explanation of the risks and benefits of inclusion. Following this, they provided their oral and written informed consent to publish the data.

Between 2008 and 2017, 14 patients (12 men and two women) with secondary thoracic and thoracolumbar kyphosis due to ankylosing spondylitis were included in the study. The indication for surgery was a progressive loss of horizontal sight due to whole spine kyphosis (chin-brow angle over $90^{\circ}$ ). The mean age at the time of operation was 47 years (range $=36-57$ years) (Table 1 ).

To assess possible injuries to the spinal cord or spinal nerves during surgery, electrophysiological monitoring of somatosensory-evoked potentials and motor-evoked potentials was carried out under general anesthesia in all patients.

After surgical exposure from $T 2$ to $L 4$, bilateral pedicle screws were placed, excluding the lumbar osteotomy levels.

Classical Smith-Petersen osteotomy (SPO) involves the removal of the posterior bony elements, including the bilateral facet joints, the inferior portion of the lamina, and the inferior portion of the spinous process, and the removal of the posterior ligaments at the osteotomy level. Forceful closure of the posterior osteotomy elongates or partially ruptures the anterior longitudinal ligament and the anterior intervertebral disc. To achieve a global correction of the kyphotic deformity, we preferred to use multiple poly-segmental posterior osteotomies, which is a modification of the classic SPO at all thoracic levels (Figure 1).

Transpedicular decancellation osteotomy is a closing wedge osteotomy usually applied on L2 or L3 level. Using smaller curettes, decancellation was begun through the pedicle. Progressively larger curettes were used with care to preserve the medial pedicle wall and posterior wall of the vertebral body. Curettage was carried out across the midline. After the removal of the pedicle walls, sequential compression on the rods until the posterior elements touched completed the closing wedge osteotomy as described in the literature before ${ }^{(8,9)}$ (Figure 2).

We started instrumentation from two levels below the lumbar osteotomy site and used bipedicular screws up to the T3 level (excluding the lumbar osteotomy site). We performed polysegmental posterior osteotomies to all thoracal levels up to T3. We used a temporary unilateral fixation of the rods when closing the wedges to prevent collapse and we used two rods for the final fixation.

Preoperatively and postoperatively, the cobb angle was measured from standing lateral radiographs of the whole spine. Operation time, blood loss, cobb angle measurements,



Figure 1. Schematic illustration of the polysegmental posterior osteotomy

Table 1. Patients' demographic data and individual angular measurements

\begin{tabular}{|c|c|c|c|c|c|c|c|c|}
\hline $\begin{array}{l}\text { Patient } \\
\text { Number }\end{array}$ & Age & Gender & $\begin{array}{l}\text { Preop chin- } \\
\text { brow angle }\end{array}$ & $\begin{array}{l}\text { Postop chin- } \\
\text { brow angle }\end{array}$ & $\begin{array}{l}\text { Preop thoracic } \\
\text { kyphosis }\end{array}$ & $\begin{array}{l}\text { Postop thoracic } \\
\text { kyphosis }\end{array}$ & $\begin{array}{l}\text { Preop lumbar } \\
\text { lordosis }\end{array}$ & $\begin{array}{l}\text { Postop lumbar } \\
\text { lordosis }\end{array}$ \\
\hline 1 & 45 & Female & $95^{\circ}$ & $15^{\circ}$ & $75^{\circ}$ & $40^{\circ}$ & $10^{\circ}$ & $-20^{\circ}$ \\
\hline 3 & 48 & Female & $98^{\circ}$ & $13^{\circ}$ & $62^{\circ}$ & $35^{\circ}$ & $-10^{\circ}$ & $-35^{\circ}$ \\
\hline 4 & 55 & Male & $105^{\circ}$ & $20^{\circ}$ & $66^{\circ}$ & $38^{\circ}$ & $5^{\circ}$ & $-23^{\circ}$ \\
\hline 7 & 40 & Male & $107^{\circ}$ & $30^{\circ}$ & $65^{\circ}$ & $38^{\circ}$ & $7^{\circ}$ & $-24^{\circ}$ \\
\hline 8 & 54 & Male & $96^{\circ}$ & $25^{\circ}$ & $66^{\circ}$ & $32^{\circ}$ & $12^{\circ}$ & $-20^{\circ}$ \\
\hline 9 & 48 & Male & $92^{\circ}$ & $12^{\circ}$ & $74^{\circ}$ & $30^{\circ}$ & $-6^{\circ}$ & $-33^{\circ}$ \\
\hline 10 & 53 & Male & $94^{\circ}$ & $10^{\circ}$ & $63^{\circ}$ & $36^{\circ}$ & $9^{\circ}$ & $-25^{\circ}$ \\
\hline 14 & 57 & Male & $95^{\circ}$ & $15^{\circ}$ & $72^{\circ}$ & $30^{\circ}$ & $13^{\circ}$ & $-22^{\circ}$ \\
\hline
\end{tabular}

Preop: Preoperative, Postop: Postoperative 
complications, chin-brow vertical angle, loss of correction at final follow-up, and early and late complications were recorded. Follow-up periods ended at the $24^{\text {th }}$ month.

\section{RESULTS}

Angular data on deformity correction, surgical time, and blood loss are listed in Table 1 and 2. There were no major perioperative and postoperative complications. Two patients had minor wound problems. Bone healing was satisfactory in all patients. Three patients had a loss of correction in thoracal regions 5,7 , and 8 degrees at the final follow-up visit. Reduction losses were acceptable, and we did not plan any revision

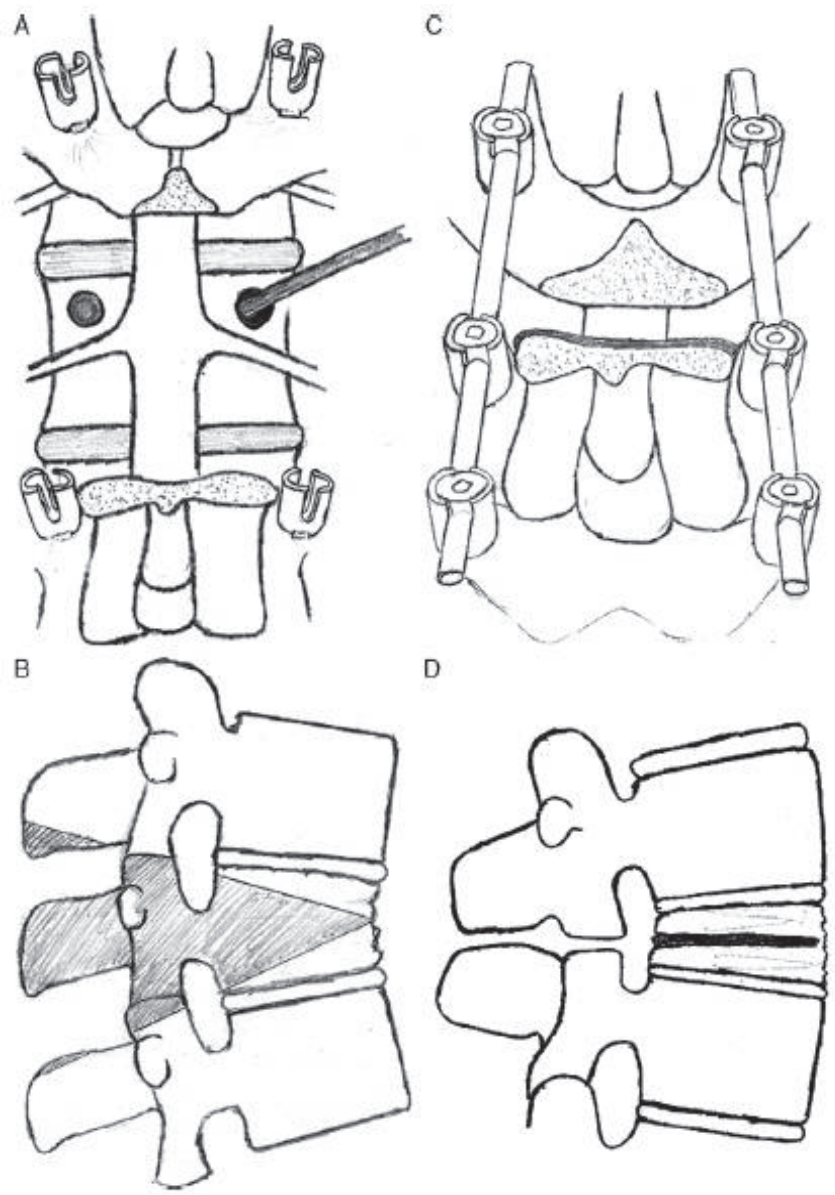

Figure 2. Schematic illustration of the lumbar decancellation osteotomy surgeries. Six patients had lumbar osteotomy at the L2 level, and eight had lumbar osteotomy at the L3 level.

Our patient sample did not include any patient with scoliotic deformity. Therefore, postoperative sagittal vertical axis and pelvic tilt measurements were within the normal range.

We did not encounter any implant-related or infection-related complications.

\section{DISCUSSION}

The principle of a lumbar spinal osteotomy is to shift the center of gravity of the trunk of the hip axis. In severe cases of ankylosing spondylitis, single-level osteotomy usually does not provide adequate correction of the kyphotic deformity; therefore, a two-level lumbar osteotomy is required ${ }^{(10,5)}$.

Smith-Petersen type osteotomy, pedicle subtraction osteotomy, and transpedicular bivertebrae wedge osteotomy procedures all aim to achieve a significant degree of correction at a single pivot point in the lumbar region ${ }^{(11,12)}$. Up to $45^{\circ}$ of correction is possible with these posterior osteotomies. However, as the desired amount of correction increases, these become surgically demanding procedures and liable to complications.

Excessive lengthening of the anterior longitudinal ligament during SPO may injure abdominal vessels. This is a rare but lethal complication ${ }^{(13,14)}$. The most commonly reported postoperative complications in SPO are intraspinal hematoma, intestinal obstruction, and superior mesenteric ischemia ${ }^{(15)}$. On the other hand, pedicle subtraction and closing wedge osteotomies are known to cause reversible and irreversible neurological complications $\mathbf{s}^{(16,17)}$. There is always a possibility of iatrogenic thecal sac or root compression during the closing of a wide wedge despite a careful surgical technique.

The safe upper limit for a closing wedge osteotomy to avoid vascular and neurological injury is considered to be $35^{\circ}$ to $40^{\circ}$ in the lumbar region ${ }^{(18-20)}$. This means that a single closing wedge osteotomy is not adequate for treating a severe kyphotic deformity in ankylosing spondylitis. In severe cases, a twolevel osteotomy is required, and at least one of them needs to force the safe upper limit ${ }^{(5)}$. Magnetic resonance imaging investigation by Liu et al. ${ }^{(21)}$ showed that closing wedge osteotomies in the lumbar region stretched the aorta and that spine surgeons should be aware of the potential vulnerability of aortic injury in ankylosing spondylitis patients undergoing closing wedge osteotomy.

Table 2. Angular data about deformity correction, surgical time, and blood loss

\begin{tabular}{|c|c|c|c|c|c|c|c|}
\hline Surgical time & Blood loss & $\begin{array}{l}\text { Preop chin- } \\
\text { brow angle }\end{array}$ & $\begin{array}{l}\text { Postop chin- } \\
\text { brow angle }\end{array}$ & $\begin{array}{l}\text { Preop } \\
\text { thoracic } \\
\text { kyphosis }\end{array}$ & $\begin{array}{l}\text { Postop } \\
\text { thoracic } \\
\text { kyphosis }\end{array}$ & $\begin{array}{l}\text { Preop lumbar } \\
\text { lordosis }\end{array}$ & $\begin{array}{l}\text { Postop lumbar } \\
\text { lordosis }\end{array}$ \\
\hline $\begin{array}{l}\text { Mean: } 281 \mathrm{~min} \\
\text { (range: } 230-350 \text { ) }\end{array}$ & $\begin{array}{l}\text { Mean: } 1870 \mathrm{~mL} \\
\text { (range: } 1200-3000 \text { ) }\end{array}$ & $\begin{array}{l}\text { Mean: } 97.5^{\circ} \\
\text { (range: } 91-107 \text { ) }\end{array}$ & $\begin{array}{l}\text { Mean: } 18^{\circ} \\
\text { (range: } 7-30 \text { ) }\end{array}$ & $\begin{array}{l}\text { Mean: } 69^{\circ} \\
\text { (range: } 58-95 \text { ) }\end{array}$ & $\begin{array}{l}\text { Mean: } 37.5^{\circ} \\
\text { (range: } 30-49 \text { ) }\end{array}$ & $\begin{array}{l}\text { Mean: }-1.2^{\circ} \\
\text { (range: }-18-13 \text { ) }\end{array}$ & $\begin{array}{l}\text { Mean: }-29^{\circ} \\
\text { [range:-20-(-42)] }\end{array}$ \\
\hline
\end{tabular}


In our study, we limited the correction obtained from transpedicular decancellation closing wedge osteotomy from $30^{\circ}$ to $35^{\circ}$. This angle limit is below the safe upper limit prescribed in previous studies. We obtained the remaining correction from multiple polysegmental posterior osteotomies in the thoracic region (Figure $3 \mathrm{~A}$ and $3 \mathrm{~B}$ ). By closing multiple posterior osteotomies over multiple segments with transpedicular fixation, a more gradual correction of the kyphosis can be achieved (Figure 4A and 4B) ${ }^{(22,23)}$. We managed to achieve $2^{\circ}$ to $5^{\circ}$ of correction for each level of polysegmental posterior osteotomy at the thoracic region. Angular correction varied depending on the anterior ligamentous ankylosis severity of the segment. This osteotomy also causes less distribution of the anterior longitudinal ligament and disc space. Hence it is safer than classic SPO, which has been known to cause a potentially high rate of complications ${ }^{(12)}$. Excessive one-level or two-level osteotomies at the lumbar region usually create a hyperlordotic posture, which is not a desired natural posture ${ }^{(24)}$. Gradual and global correction also avoided hyperlordosis in our patients.
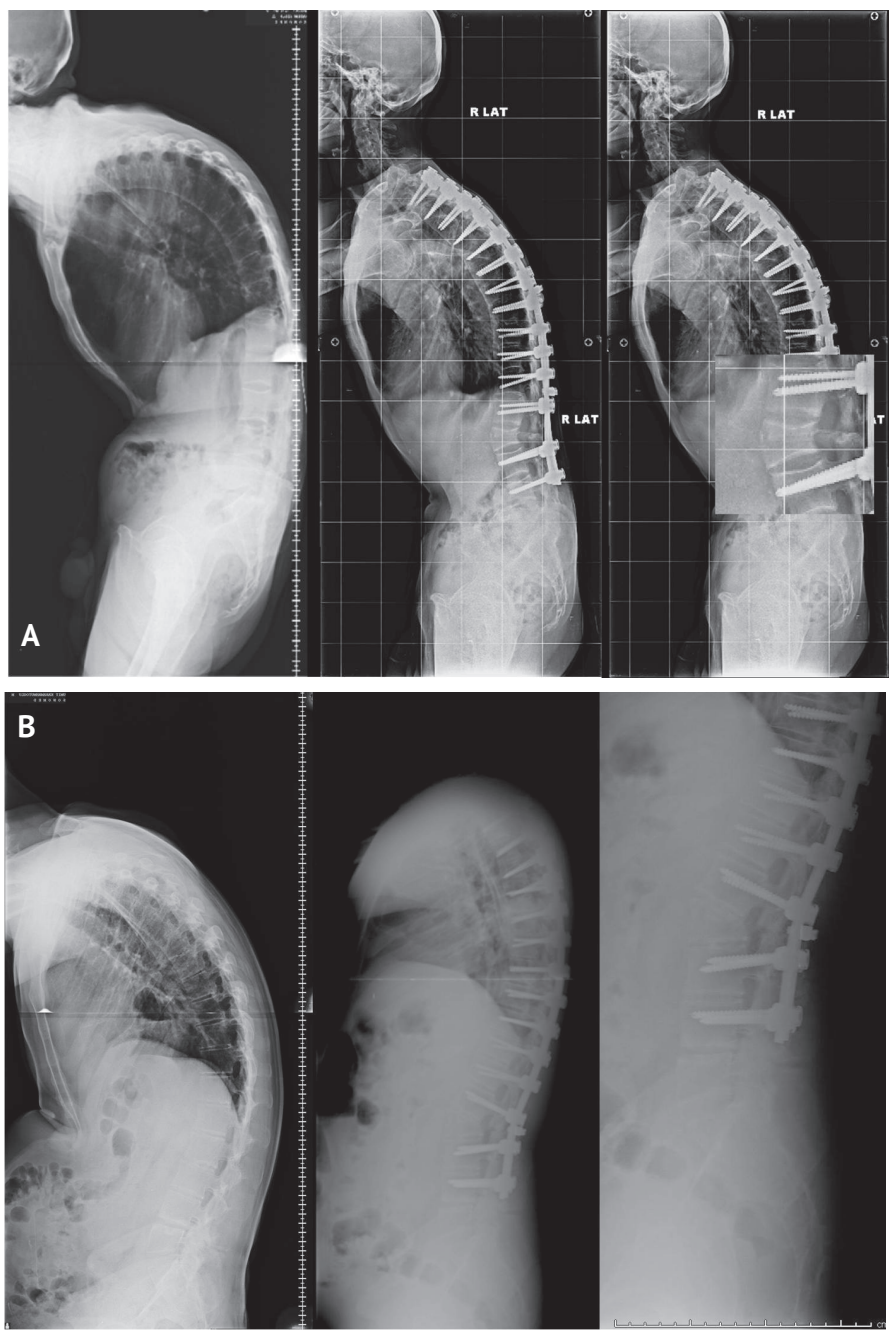

Figure 3. Preoperative (A) and final follow-up (B) radiographs of patients highlighting the lumbar osteotomies
We did not encounter any major or minor vascular-neurological complications in our study. We only encountered minor wound healing problems in two patients.

\section{Study Limitations}

There are some limitations in our study. Depending on our clinical experience and experimental studies, we used bipedicular screws up to the T3 level to distribute pull-out force on as many screws as possible ${ }^{(25)}$. However, we are unable to make a statement about the necessity of bipedicular screw placement of all levels. Also, although our results are promising, we are still collecting data of our patients and a larger patient sample will provide more data in future studies.

\section{CONCLUSION}

Although a longer construct is more prone to causing skin problems and is more costly, global and gradual correction of kyphosis in ankylosing spondylitis with our technique provided satisfactory correction without major vascular-neurologic complications. Our study has showed that this method is as effective as two-level lumbar osteotomies used in severe cases and a safer procedure. Using this procedure, we also avoided
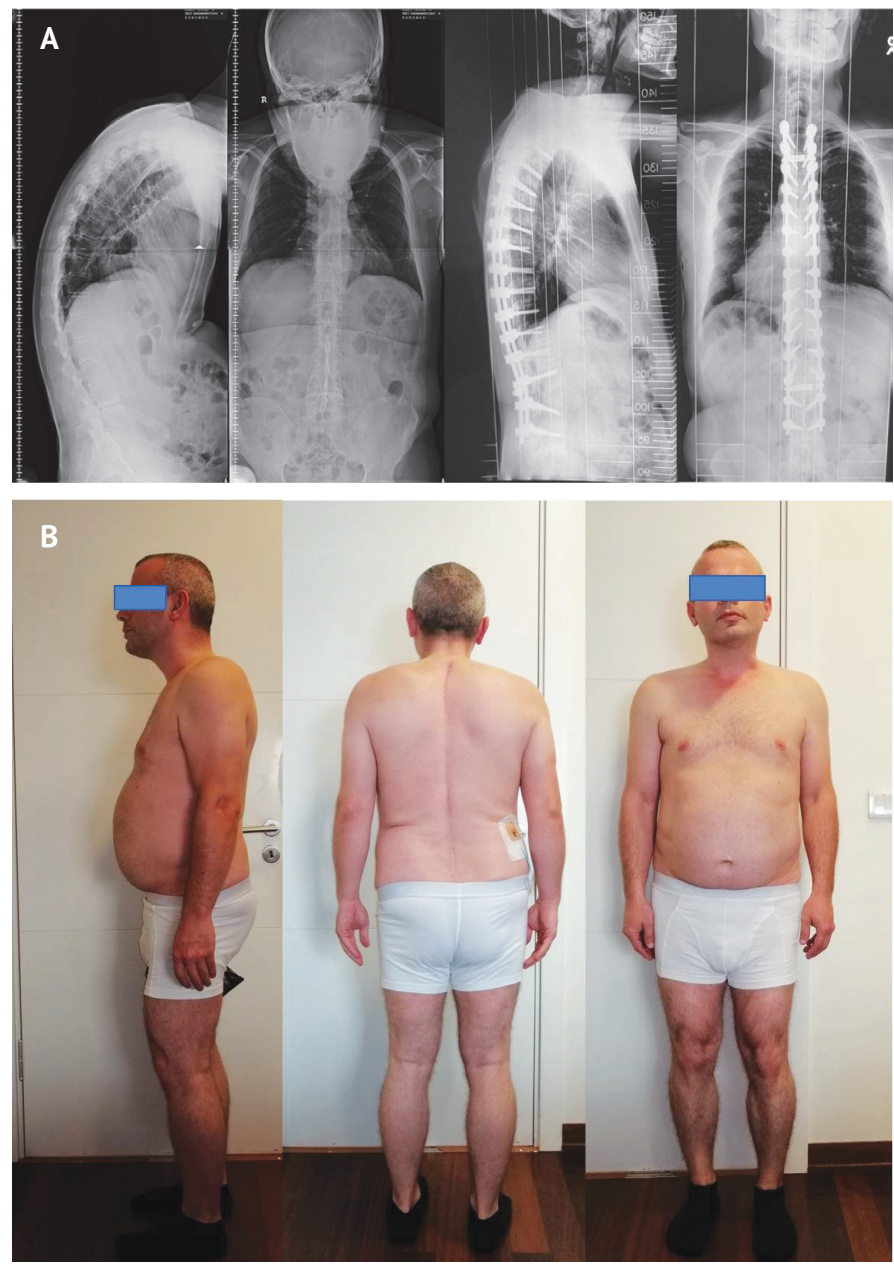

Figure 4. Gradual correction of the thoracic deformity (A) and patient posture in the final follow-up (B) 
hyperlordotic posture, corrected thoracal kyphosis, and gained a more natural sagittal curvature in all the patients.

\section{Ethics}

Ethics Committee Approval: Approval from the General Clinical Directorate of Academic Hospital was obtained before starting the data collection of patients included in the study. The study was performed by the ethical standards of the 1964 Declaration of Helsinki as revised in 2000 and those of Good Clinical Practice (approval number: 10/01/2019-12).

Informed Consent:All subjects participating in this retrospective study received a thorough explanation of the risks and benefits of inclusion. Following this, they provided their oral and written informed consent to publish the data.

\section{Authorship Contributions}

Concept: M.B., Design: M.B., Data Collection or Processing: G.K., Analysis or Interpretation: G.K., Literature Search: G.K., Writing: G.K.,

Conflict of Interest: No conflict of interest was declared by the authors.

Financial Disclosure: The authors declared that this study received no financial support.

\section{REFERENCES}

1. Smith-Petersen MN, Larson CB, Aufrance OE. Osteotomy of the spine for correction of flexion deformity in rheumatoid arthritis. Clin Orthop. 1969;66:6-9.

2. Jaffray $\mathrm{D}$, Becker V, Elsenstein S. Closing wedge osteotomy with transpedicular ş fixation in ankylosing spondylitis. Clin Orthop. 1992;279:122-6.

3. Thomasen E. Vertebral osteotomy for correction of kyphosis in ankylosing spondylitis. Clin Orthop. 1985;194:142-52.

4. Thiranant N, Netrawichien P. Transpedicular decancellation closed wedge vertebral osteotomy for treatment of Şfixed şflexion deformity of spine in ankylosing spondylitis. Spine (Phila Pa 1976). 1993; 18:2517-22.

5. Zheng GQ, Song K, Zhang YG, Wang Y, Huang P, Zhang XS, et al. Two-level spinal osteotomy for severe thoracolumbar kyphosis in ankylosing spondylitis. Experience with 48 patients. Spine (Phila Pa 1976). 2014;39:1055-8.

6. Van Royen B], De Gast A. Lumbar osteotomy for correction of thoracolumbar kyphotic deformity in ankylosing spondylitis: a structured review of three methods of treatment. Ann Rheum Dis. 1999;58:399-406

7. Chen IH, Chien JT, Yu TC. Transpedicular wedge osteotomy for correction of thoracolumbar kyphosis in ankylosing spondylitis experience with 78 patients. Spine (Phila Pa 1976). 2001;26:E35460 .

8. Bezer M, Kucukdurmaz F, Guven O. Transpedicular decancellation osteotomy in the treatment of post tuberculous kyphosis. J Spinal Disord Tech. 2007;20:209-15.
9. Murrey DB, Brigham CD, Kiebzak GM, Finger F, Chewning SJ. Transpedicular decompression and pedicle subtraction osteotomy (eggshell procedure). Spine (Phila Pa 1976). 2002;27:2338-45.

10. Song K, Zheng GQ, Zhang YG, Zhang X, Mao K, Wang Y. A new method for calculating the exact angle required for spinal osteotomy. Spine (Phila Pa 1976). 2013;38:E616-20.

11. Wang Y, Zhang Y, Mao K, Zhang X, Wang Z, Zheng G, et al. Transpedicular bivertebrae wedge osteotomy and discectomy in lumbar spine for severe ankylosing spondylitis. J Spinal Disord Tech. 2010;23:186-91.

12. Ayhan S, Aykac B, Yuksel S, Guler UO, Pellise F, Alanay A, et al; ESSC European Spine Study Group. Safety and efficacy of osteotomies in adult spinal deformity: what happens in the first year? Eur Spine J. 2016;25:2471-9.

13. LiuH, YangC, ZhengZ, Ding W, Wang J, Wang H, et al. Comparison of Smith-Petersen osteotomy and pedicle subtraction osteotomy for the correction of thoracolumbar kyphotic deformity in ankylosing spondylitis: a systematic review and meta-analysis. Spine (Phila Pa1976). 2015;40:570-9.

14. Arun R, Dabke HV, Mehdian H. Comparison of three types of lumbar osteotomy for ankylosing spondylitis:a caseseries and evolution of a safe technique for instrumented reduction. Eur Spine J. 2011;20:2252-60.

15. Halim A, Kiester D, Lee YP. Smith-Petersen and pedicle subtraction osteotomies. Seminars in Spine Surgery. 2017;29:91-9.

16. KimK-T, LeeS-H, SukK-S, LeeJ-H, JeongB-O. Outcome of pedicle subtraction osteotomies for fixed sagittal imbalance of multiple etiologies: a retrospective review of 140 patients. Spine (PhilaPa1976). 2012;37:1667-75.

17. Cho K-J, Bridwell KH, Lenke LG, Berra A, Baldus C. Comparison ofSmithPetersen versus pedicle subtraction osteotomy for the correction of fixed sagittal imbalance. Spine (PhilaPa 1976). 2005;30:2030-7.

18. Chang KW, Cheng CW, Chen HC, Chang KI, Chen TC. Closingopening wedge osteotomy for the treatment of sagittal imbalance. Spine (Phila Pa 1976). 2008;33:1470-7.

19. Lehmer SM, Keppler L, Buscup RS, Enker P, Miller SD, Steffee AD. Posterior transvertebral osteotomy for adult thoracolumbar kyphosis. Spine (Phila Pa 1976). 1994;19:2060-7.

20. Gertzbein SD, Harris MB. Wedge osteotomy for the correction of posttraumatic kyphosis. Spine (Phila Pa 1976). 1992;17:374-9.

21. Liu H, Qian BP, Qiu Y, Mao SH, Qu Z, Wang B, et al. Does the Traversing Length of the Aorta Change After Closing Wedge Osteotomy for Ankylosing Spondylitis Patients With Thoracolumbar Kyphosis?: A Magnetic Resonance Imaging Investigation. Spine (Phila Pa 1976). 2017;42:106-12.

22. Sansur CA, Fu KM, Oskouian Jr RJ, Jagannathan J, Kuntz 4th C, Shaffrey $\mathrm{Cl}$. Surgical management of global sagittal deformity in ankylosing spondylitis. Neurosurg Focus. 2008;24:E8.

23. Dorward IG, Lenke LG. Osteotomies in the posterior- only treatment of complex adult spinal deformity: a comparative review. Neurosurg Focus. 2010;28:E4.

24. Kiaer T, Gehrchen M. Transpedicular closed wedge osteotomy in ankylosing spondylitis: results of surgical treatment and prospective outcome analysis. Eur Spine. J 2010;19:57-64.

25. Bezer M, Ketenci IE, Saygi B, Kiyak G. Bicortical versus unicortical pedicle screws in direct vertebral rotation: an in vitro experimental study J Spinal Disord Tech. 2012;25:E178-82. 